\title{
Individualism-Collectivism as the Dimension Distinguishing the Western from the Eastern Culture
}

\author{
DaYeon Her $^{1}$, HyunGyung Joo ${ }^{2}$ \\ ${ }^{1}$ Department of Psychology, Miami University, Ohio, USA \\ ${ }^{2}$ Department of Graduate and Professional Studies, California State University, Sacramento, CA, USA \\ Correspondence: DaYeon Her, Department of Psychology, Miami University, Ohio, USA.
}

Received: May 31, 2018

doi:10.11114/ijsss.v6i7.3324
Available online: June 22, 2018

URL: https://doi.org/10.11114/ijsss.v6i7.3324

\begin{abstract}
Individualism (IND)-collectivism (COL) has been the most popular dimension separating the West from the East. As the recent findings relating to IND-COL by national and ethnic groups become divergent, however, some investigators are challenging IND-COL as the most representative framework dividing into the West and the East. For this reason, focusing on some issues that are supposed to cause inconsistent findings regarding IND-COL, it requires making IND-COL investigations examined and, in turn, elaborated. In the context of supporting the elaboration, this review tries to provide some suggestions as follows. First, it is necessary to analyze and set up the concept of IND-COL precisely. Second, cultural psychologists need to elaborate instruments and introduce social-ecological variables, cultural products, and qualitative approach. Third, there need to diversify the sampling target. Fourth, future research requires specifying the sampling target more specifically. Fifth, IND-COL studies need to solve the issue due to the level of analysis.
\end{abstract}

Keywords: individualism (IND), collectivism (COL), Americans, East Asians, cultural psychology

\section{Introduction}

Individualism (IND)-collectivism (COL) has held the top spot among representative dimensions distinguishing the West from the East for many years (Schwartz, 1990; Triandis, 2004; Triandis \& Gelfand, 1998). In general, IND assumes that individuals are independent of one another whereas COL supposes that groups bind and obligate individuals (Hofstede, 1980). As such, individualistic culture supports a view of self as self-directed, autonomous, and separate from others and focuses on discovering and expressing differences among members (Santos, Varnum, \& Grossmann, 2017; Zha, Walczyk, Griffith-Ross, Tobacyk, \& Walczyk, 2006). Conversely, collectivistic cultures emphasize mutual obligations, harmonies, and expectations based on statuses and give priority to in-group goals rather than personal goals (Schwartz, 1990; Triandis, 2004).

So far, a substantial body of research showed that IND-COL, which reflects distinctly contrasting worldview, influenced various components of individuals and organizations. Specific components can be self-construals, personality, creativity, locus of control, communication, conversational style, well-being, help-seeking, and workplaces (Kim et al., 1996; Hofstede, 2006; Markus \& Kitayama, 2010; Merkin, 2018; Sandoval \& Lee, 2006; Spector et al. 2001; Wated \& Sanchez, 2015; Zha et al., 2006). To be more specific, arguing sociocultural backdrop of personality, Kim et al. (1996) showed that IND-COL influenced self-construals which, in turn, was correlated with conversational styles. Analyzing on data collected from managers in twenty-four nations, Spector et al. (2001) also found that IND-COL showed a substantial relationship with an internal locus of control, and, subsequently, the results at the ecological level coincided with the previous research supporting the salutary effect of internal locus of control on well-being. Besides, Sandoval and Lee (2006) revealed that collectivist norms incite individuals to reduce differences as soon as possible and facilitate more interdependencies than individualist ones do and, consequently, there would be more common help-seeking in collectivist organizations, compared with individualist ones.

However, some recent findings have shown that individualistic-collectivistic difference between Americans and East Asians, who respectively represent the West and the East, was somewhat divergent (Benet-martínez \& Karakitapoğlu-aygün, 2003; Matsumoto, Weissman, Preston, Brown, \& Kupperbusch, 1997; Oyserman, Coon, \& Kemmelmeier, 2002). As a good example, Oyserman et al. (2002) performing meta-analysis found that the effect size 
was not only small, but also applied to only Chinese groups, objecting the instrument, classification, measurement method, and even concept itself. Other than that, Matsumoto et al. (1997) found not only that collectivistic level was significantly different in Japanese and Korean sample belonging to the same East Asian, but also that Japanese sample was not more collectivistic than the American sample. As a result of reviewing these recent results, some researchers (Chen, 2015; Santos et al., 2017) raised the possibility that it reflected cultural acculturation through rapid globalization and modernization.

Inevitably, IND-COL, which has enjoyed enormous popularity as the framework of distinguishing the West and the East, is in an overall crisis for the first time since IND-COL made an appearance in cultural psychology (Benet-martínez \& Karakitapoğlu-aygün, 2003; Fiske, 2002; Matsumoto et al., 1997; Schwartz, 1990). However, even Oyserman et al. (2002) who sharply criticized IND-COL investigations admitted that IND-COL was still the significant viewpoint. Besides, Fiske (2002) who cut cultural psychologists' IND-COL works to pieces suggested some alternatives to overcome the limitation of IND-COL works. Moreover, some researchers still supported IND-COL as pretty good framework separating the West from the East until quite recently (Hamamura, 2012). After all, if investigators accept criticism of IND-COL research actively and advance, this challenge would be a blessing in a guise that IND-COL is a lot more elaborated rather than wholly dismissed in cultural psychology. As a way for an elaboration, therefore, this study will discuss five suggestions for solving some issues regarding IND-COL works which researchers have raised. The five issues to solve are about clarifying the concept, elaborating the method to measure and study, diversifying the sampling target, specifying the sampling target, and solving issue due to the level of analysis.

\section{Literature Review}

As mentioned above, this study intends to discuss suggestions along with some issues centering on clarifying the concept, elaborating the method to measure and study, diversifying the sampling target, specifying the sampling target in more detail, and solving issue due to the level of analysis as follows.

First, it requires examining precisely and establishing the concept of IND-COL through in-depth and insightful discussion among many investigators. To this day, cultural psychologists have defined the concept of IND-COL differently. Initially, Hofstede (1980) considered it as the opposite attributes in the same dimension, whereas Triandis (2004), Triandis and Gelfand (1998) saw it as horizontal and vertical IND-COL. Psychologists supporting these many dimensions argued that IND-COL could coexist in society instead of the opposite attributes in the same dimension (Schwartz, 1990). Furthermore, Oyserman et al. (2002) emphasized on requiring a tighter operationalization of IND-COL, suggesting the introduction of the core concepts such as the personal independence (for individualism) and the obligation and duty to the in-group (for collectivism). With criticizing this loose operationalization, Oyserman et al. (2002) expressed an opinion that many IND-COL tests were likely to measure such different concepts due to these different IND-COL concepts.

Contrary to Oyserman et al. (2002), Fiske (2002) objected a perspective of IND-COL researchers, suggesting that culture is a socially transmitted or constructed constellation consisting of practices, symbols, values, norms, institutions, constitutive rules, artifacts, modifications of the physical environment, and others. Considering the concept of culture that Fiske (2002) proposed, we should never understand culture as a trait of an individual, nor can understand it as the mean scores of the traits of some group configured with individuals. In other words, according to Fiske (2002), even if we include the core concepts of IND-COL through a tighter operationalization as Oyserman et al. (2002) suggested, it is not culture. Furthermore, Fiske (2002), like Schwartz (1990), determinedly mentioned that IND is not the opposite of COL. Building on above discussion, there is a need to establish the concept of IND-COL through thoughtful discourses among investigators in a variety of areas including psychologists, anthropologists, and sociologists. As a result of earnest discourses and critical reflection, it is expected that cultural psychologists may be willing to make participant observation, with the acceptance that culture is a socially transmitted or constructed constellation. The practical and specific discussion surrounding the concept of IND-COL will be continued in dealing with the method to measure and research IND-COL, as described below.

Second, cultural psychologists need to not only elaborate objective instruments but also introduce social-ecological variables, cultural products, and qualitative approach actively. To do this, researchers construct preliminary tests assessing the correct constructs of IND-COL and then go through validation procedure for developing an elaborate test (Matsumoto et al., 1997; Triandis, 2004; Triandis \& Gelfand, 1998). In fact, Matsumoto et al. (1997), Triandis (2004), and Triandis and Gelfand (1998) made much effort to construct an IND-COL test with higher reliability and validity. Nonetheless, Oyserman et al. (2002) still raised strong objections to existing IND-COL tests. Thus, in an objective IND-COL test, there is a need to contain the core concepts which Oyserman et al. (2002) suggested. Besides, researchers need to integrate social-ecological variables into an IND-COL test. Such variables are subsistence, economic systems, religion, kinship systems, relational models, sex, food, institutions and practices as social-ecological 
variables which Fiske (2002) suggested. Except for measuring these adequate contents, of course, there need to explore the appropriate methods to measure such contents. The reason relates to Fiske's comment (2002) that items, which were composed of first-person statements, are challenging to assess culture appropriately. In addition to this, it is necessary to consider that participants can be a bit strange to such an IND-COL test in a particular culture. After all, investigators need to search for the method to measure appropriate contents adequately.

Except for effort to improve the reliability and validity of an IND-COL test, investigators need to introduce particular situations, cultural products, depth interview, and participant observation (Fiske, 2002; Georgas, van de Vijver, \& Berry, 2004; Kim et al., 1996; Morling \& Lamoreaux, 2008). First of all, it may provide a small sample with some particular communication situations (for example, request situations), reflecting related phenomenon, and observe the response of participants (Kim et al., 1996). Above these, Morling and Lamoreaux (2008) analyzed cultural products such as texts, media, and physical object except for appropriate statistics to calculate the effect size and, in turn, obtained a positive effect. Further, IND-COL researchers should consider depth interview and participant observation if possible. In particular, if the long-term participant observations were available, participant observers would be able to understand even phenomena to hardly measure via an objective instrument, for example, a naïve dialectic in East Asia. Indeed, a naïve dialectic, which accepts contradiction and expects a change in everyday life (Peng \& Nisbett, 1999), is seldom assessed accurately by an objective test. Perhaps the primary reason is due to social desirability except for the unique characteristics of culture. Similarly, any components of IND-COL, just as naïve dialectic, can hardly be revealed by an objective IND-COL test. Therefore, there needs to explore the appropriate method to understand a culture. Consequently, to read a culture adequately, cultural psychologists can try to administer an objective test including core elements and social-ecological variables in the whole samples (Chen et al., 2015; Georgas \& Berry, 1995; Georgas et al., 2004). Along with this, they will be able to apply some particular situations, cultural products, depth interview, or participant observation to some samples (Hamamura, 2012).

Third, the sampling target should be diversified, contrary to many studies that mainly used college samples. In fact, college students may be the samples of many studies thanks to the availability of sampling. Whether the West or the East, however, the college students generally are more individualistic than other groups, and, consequently, are less likely to be a difference of the West and the East (Oyserman et al., 2002). The reason for that lies in that they have a higher level of education, come from a higher socioeconomic background, and usually are the least restricted by others, job, and time and place. Moreover, now when individualism increases all over the world by recent acceleration of globalization, there is a possibility that college students may be exposed to such a trend (Chen, 2015; Santos et al., 2017). As a result, college students have high chance to be the primary beneficiary of modernization effect.

Objecting Some researchers(Oyserman et al., 2002; Santos et al., 2017), however, Fiske (2002) presented the contradictory findings that nonstudent samples tended to be smaller IND differences between European Americans and Asian Americans, compared with student samples. From a slightly different angle, furthermore, IND-COL may relate to even cultural heritage theory except for modernization effect (Hamamura, 2012). As a result, the opinions of Fiske and Hamamura imply that college student samples did not cause small effect sizes for IND-COL differences between Americans and East Asians. As such, researchers need to beware lest should jump to a hasty conclusion that college student samples cause no difference or a razor-thin margin in IND-COL between Americans and East Asians. Considering both sides as noted above, cultural psychologists need to diversify a sampling target for understanding various cultural complexions and enhancing the generalizability of the results, regardless of whether or not the significant difference exists.

Fourth, researchers should need to specify the sampling target in more detail. That is, there is a need to subdivide East Asian into Korean, Japanese, and Chinese and at the same time do American into European, African, and Latin American. The reason for this lies in that, even if some countries are in the same continental, there can be a delicate difference from country to country because each country still holds indigenous cultural legacies, being seldom offset by rapid globalization and modernization effect (Hamamura, 2012). Indeed, Koreans and Japanese wake up to a realization of the fact that they differ from each other. Some investigations already confirm some individualistic-collectivistic difference among Korean, Chinese, and Japanese and between European and Hispanic Americans (Benet-martínez \& Karakitapoğlu-aygün, 2003; Matsumoto et al., 1997; Oyserman et al., 2002). To put it concretely, Matsumoto et al. (1997) found that Japanese sample, unlike South Koreans, was not more collectivistic than American sample, and, surprisingly, South Koreans are more similar to Americans far away in values and behaviors regarding family, rather than Japanese.

For many years, however, a substantial body of research on individualistic-collectivistic difference still have just lumped race or nation together as American, Asian American, or East Asian (Benet-martínez \& Karakitapoğlu-aygün, 2003; Hammack, 2018; Zha et al., 2006). Even, when investigators specify sampling targets such as Korean, Japanese, and Chinese, African American, and Hispanic American in the investigations comparing the East with the West, nearly 
most investigators tended to do so in only one of compared two groups. Usually, this problem raised in IND-COL research was attributed to the availability of sampling. Other reason can be US centered grouping such as Americans and Asians, albeit Korean, Japanese, and Chinese and so on exist within Asian (Hammack, 2018). Whatever the reason, to understand a culture correctly, researchers must select the appropriate sampling target to the research purpose, hardly depending on the convenience of sampling and US-centered grouping.

Fifth, it needs to solve the issue due to the level of analysis when investigators study individualistic-collectivistic differences by the Western and the Eastern culture. Typically, cross-cultural psychologists try to grasp the relationship between individual behaviors and the cultural contexts in which they are shaped and revealed (Georgas et al., 2004). At this time, researchers typically measure individual responses to an IND-COL test by self-report, yield mean scores for a cultural sample and then regard them as a nation's IND-COL scores (Benet-martínez \& Karakitapoğlu-aygün, 2003; Georgas \& Berry, 1995; Nakata, 2009). In fact, these nation's IND-COL scores are essentially psychological and are measured according to the psychological procedure. Nonetheless, researchers tend to equate these nation's IND-COL scores with IND-COL indicators assessed at the national level. Consequently, this process causes onomastic fallacy, in which the name of a nation is utilized to identify the culture and serves as a substitute for the cultural variables that account for the cultural phenomenon (Georgas \& Berry, 1995; Georgas et al., 2004; Nakata, 2009). To obtain a nation's adequate IND-COL indicators, conversely, investigators need to study cultures at ecological contexts with ethnographic methods, utilizing concepts that relate populations to their habitat (Georgas et al., 2004).

Continually, onomastic fallacy, as has just been mentioned, leads to a tautology, too. The reason is caused by the fact that, after assuming mean of individual IND-COL scores as a nation's IND-COL indicators, investigators try to test various individual traits by these assumed nation's IND-COL indicators. In this way, if researchers use these assumed nation's IND-COL indicators as a predictor variable, the correlations between a nation's IND-COL indicators and various individual traits are more likely to be high (Benet-martínez \& Karakitapoğlu-aygün, 2003). Those significant relationships would be similar to a tautology. Criticizing this tautological phenomenon, accordingly, Smith (2004) emphasized the necessity of using a nation's real IND-COL indicators rather than a nation's IND-COL scores assessed at the individual level. To overcome onomastic fallacy and tautological phenomenon due to the level of analysis, finally, psychologists should study cultural contexts directly and independently and use a nation's real IND-COL indicators (Georgas \& Berry, 1995; Georgas et al., 2004; Fiske, 2002; Nakata, 2009).

\section{Conclusion}

The above discussion provided some suggestions focusing on issues such as clarifying the concept, elaborating the method to measure and study, diversifying the sampling target, specifying the sampling target in more detail, and solving issue due to the level of analysis which researchers have mainly raised. As we have seen, fortunately, some psychologists already seemed to be searching for a way of solving some issues exposed (Chen et al., 2015; Fiske, 2003; Hamamura, 2012; Morling \& Lamoreaux, 2008; Santos et al., 2017). As an example, performing a meta-analysis including cultural products, Morling and Lamoreaux (2008) got larger effect size than Oyserman et al. (2002) did. Such result can be considered as a little fruit that investigators elaborated IND-COL research, and perhaps this effort for elaborating IND-COL research continuously produce a more meaningful and precious lot of findings. As a result, taken together, the severe criticism, which Oyserman et al. (2002) and Fiske (2002) did, appear to serve as the best booster for a renewal of IND-COL research. That is, they spurred cultural psychologists to look at the unique area of culture just as they are rather than to categorize and compare hastily. Following this momentum, it is expected that cultural psychologists continuously seem to make the most of opportunities of not only elaborating research methods and measurements, but also taking an interest in subjective, dynamic, and changing aspects of this topic. Along with this trend, as rapid modernization and globalization emerge throughout the world, the discussion among psychologists on this topic cannot be the same appearance it used to be. Finally, by the change of times, though emerging issues relating to cultural psychology will a little change, the topic of IND-COL is expected to produce meaningful and advanced studies continually.

\section{References}

American Psychological Association. (1972). Ethical standards of psychologists. Washington, DC: American Psychological Association.

Benet-martínez, V., \& Karakitapoğlu-aygün, Z. (2003). The interplay of cultural syndromes and personality in predicting life satisfaction. Journal of Cross-Cultural Psychology, 34(1), 38-60. http://doi.org/10.1177/0022022102239154

Chen, R. (2015). Weaving individualism into collectivism: Chinese adults' evolving relationship and family values. Journal of Comparative Family Studies, 46(2), 167-179. 
Chen, X., Gong, J., Yu, B., Li, S., Striley, C., Yang, N., \& Li, F. (2015). Construct, concept mapping, and psychometric assessment of the concise scale of individualism-collectivism. Social Behavior and Personality, 43(4), 667-684. http://doi.org/10.2224/sbp.2015.43.x.xxx

Fiske, A. P. (2002). Using individualism and collectivism to compare culture-A critique of the validity and measurement of the constructs: Comment on Oyserman et al. Psychological Bulletin, 128(1), 78-88. http://doi.org/10.1037//0033-2909.128.1.78

Georgas, J., \& Berry, J. W. (1995). An ecocultural taxonomy for cross-cultural psychology. Cross-Cultural Research, 29, 121-157. http://doi.org/10.1177/106939719502900202

Georgas, J., van de Vijver, F. R., \& Berry, J. W. (2004). The ecocultural framework, ecosocial indices, and psychological variables in cross-cultural research. Journal of Cross-Cultural Psychology, 35(1), 74-96. http://doi.org/10.1177/0022022103260459

Hamamura, T. (2012). Are cultures becoming individualistic? A cross-temporal comparison of individual-collectivism in the United States and Japan. Personality and Social Psychological Review, 16(1), 3-24. http://doi.org/10.1177/1088868311411587

Hammack, P. L. (2018). The Oxford handbook of social psychology and social justice. Oxford: Oxford University Press. http://dx.doi.org/10.1093/oxfordhb/9780199938735.001.0001

Hofstede, G. (1980). Culture's consequences: International differences in work-related values. Beverly Hills, CA: Sage.

Hofstede, G. (2006). What did GLOBE really measure? Researchers' minds versus respondents' minds. Journal of International Business Studies, 37, 882-896. http://doi.org/10.1057/palgrave.jibs.8400233

Kim, M. S., Hunter, J. E., Miyahara, A., Horvath, A. M., Bresnahan, M., \& Yoon, H. J. (1996). Individual-vs.culture-level dimensions of individualism and collectivism: Effects on preferred conversational styles. Communication Monograph, 63, 29-49. http://doi.org/10.1080/03637759609376373

Markus, H., \& Kitayama, S. (2010). Cultures and selves: A cycle of mutual constitution. Perspectives on Psychological Science, 5(4), 420-430. http://doi.org/10.1177/1745691610375557

Matsumoto, D., Weissman, M. D., Preston, K., Brown, B. R., \& Kupperbusch, C. (1997). Context-specific measurement of individual-collectivism on the individual level: The individual-collectivism interpersonal assessment inventory. Journal of Cross-Cultural Psychology, 28(6), 743-767. http://doi.org/10.1177/0022022197286006

Merkin R. S. (2018). Individualism-collectivism applied to direct versus indirect facework. In R. S. Merkin, Saving face in business. NY: Palgrave Macmillan. https://doi.org/10.1057/978-1-137-59174-6_5

Morling, B., \& Lamoreaux, M. (2008). Measuring culture outside the head: A meta-analysis of individualism-collectivism in cultural products. Personality and Social Psychology Review, 12(3), 199-221. http://doi.org/10.1177/1088868308318260

Nakata, C. (2009). Beyond Hofstede: Culture frameworks for global marketing and management. Chicago: Macmillan.

Oyserman, D., Coon, H. M., \& Kemmelmeier, M. (2002). Rethinking individualism and collectivism: Evaluation of theoretical assumptions and meta-analyses. Psychological Bulletin, 128(1), 3-72. http://doi.org/10.1037//0033-2909.128.1.3

Peng, K., \& Nisbett, R. E. (1999). Culture, dialectics, and reasoning about contradiction. American Psychologist, 54(9), 741-754. http://doi.org/10.1037/0003-066X.54.9.741

Sandoval, B., \& Lee, F. (2006). When is seeking help appropriate? How norms affect help seeking in organizations. In S. Karabenick and R. Newman (Eds.), New directions in help seeking. NY: Routledge.

Santos, H. C., Varnum, M. E. W., \& Grossmann, I. (2017). Global increases in individualism. Psychological Science, 28(9), 1228-1239. http://doi.org/10.1177/09567976177006

Schwartz, S. H. (1990). Individualism-collectivism: Critique and proposed refinements. Journal of Cross-Cultural Psychology, 21, 139-157. http://doi.org/10.1177/0022022190212001

Smith, P. B. (2004). Nations, cultures, and individuals: New perspectives and old dilemmas. Journal of Cross-Cultural Psychology, 35(1), 6-12. http://doi.org/10.1177/0022022103260460

Spector T. E. et al. (2001). Do national levels of individualism and internal locus of control relate to well-being: An ecological level international study. Journal of Organizational Behavior, 22, 815-832. http://doi.org/10.1002/job.118 
Triandis, H. C. (2004). The many dimensions of culture. Academy of Management Executive, 18(1), 88-93. http://doi.org/10.5465/ame.2004.12689599

Triandis, H. C., \& Gelfand, M. J. (1998). Converging measurement and horizontal and vertical individualism and collectivism. Journal of Personality and Social Psychology, 74(1), 118-128. http://doi.org/10.1037/0022-3514.74.1.118

Wated, G., \& Sanchez, J. I. (2015). Managerial tolerance of nepotism: The effects of individualism-collectivism in a Latin American context. Journal of Business Ethics, 130(1), 45-47. https://doi.org/10.1007/s10551-014-2195-7

Zha, P., Walczyk, J. J., Griffith-Ross, D. A., Tobacyk, J. J., \& Walczyk, D. F. (2006). The impact of culture and individualism-collectivism on the creative potential and achievement of American and Chinese adults. Creativity Research Journal, 18(3), 355-366. http://doi.org/10.1207/s15326934crj1803_10

\section{Copyrights}

Copyright for this article is retained by the author(s), with first publication rights granted to the journal.

This is an open-access article distributed under the terms and conditions of the Creative Commons Attribution license which permits unrestricted use, distribution, and reproduction in any medium, provided the original work is properly cited. 